Senior researcher Radu LUPU, PhD

Institute for Economic Forecasting, Romanian Academy

The Bucharest University of Economic Studies

E-mail: radulupu.ase@gmail.com

Senior researcher Adrian Cantemir CALIN, PhD

Institute for Economic Forecasting, Romanian Academy

The Bucharest University of Economic Studies

E-mail: cantemircalin@ipe.ro

Associate professor Ana Barbara BOBIRCA, PhD

The Bucharest University of Economic Studies

E-mail: anabobirca@yahoo.com

Professor Paul Gabriel MICLAUS, PhD

The Bucharest University of Economic Studies

E-mail: pmiclaus@gmail.com

\title{
STOCK MARKET FRAGILITY FOR MACROPRUDENTIAL POLICIES IN EASTERN EUROPEAN COUNTRIES
}

\begin{abstract}
The financial crisis of 2008 demonstrated the powerful relations that exist among financial institutions and the way in which these connections catalyse the shocks that flog the financial system. This interdependency was translated into a wave of academic attention towards the measurement and mitigation of systemic risk. The purpose of this paper is to propose a measure of the contribution of each country in our sample to the fragility of the entire Eastern European capital market. Our results indicate that this measure is strongly dependent on the perceptions of economic policies as measured by the European Commission through the Economic SentiMent indices.
\end{abstract}

Keywords Macroeconomic prudential policies, financial stability, fragility, absorption ratio, systemic risk.

JEL Classification G15, G17, G19

DOI: $10.24818 / 18423264 / 52.4 .18 .02$ 
Radu Lupu, Adrian Cantemir Calin, Ana Barbara Bobirca, Paul Gabriel Miclaus

\section{Introduction}

The extensive glossary of financial crises has led a body of literature to conjecture that past financial regulatory initiatives were unable to guide towards a stable financial system in its entirety. Crockett (2000), Borio (2003), Knight (2006), White (2006), or Borio (2011) among others highlighted certain shortcomings among which the most dominant feature was the fact that classical regulatory measures had a micro-based approach.

The recent financial crises cemented the idea that microprudential measures, namely actions that ensure the well-being and safety of individual institutions, are not sufficient from a systemic perspective. This paved the way for macroprudential policies that represent a complement for the above mentioned measures, in a bid to guarantee financial stability (IMF (2011)).

Galati and Moessner (2013) note that there is not a uniform perspective in the specific literature on the objectives of macroprudential policy, as two approaches coexist in defining financial stability. The first perceives stability as a form of robustness under the influence of external shocks. The parallel stream of though defines financial stability as a measure of resilience to shocks that have their origin within the system or as a form of vulnerability to normal-sized shocks (Galati and Moessner (2013)).

Our paper is related to the literature that focuses on financial fragility. Tymoigne (2014) expands the definition of Minsky (1986) highlighting the fact that financial fragility is given by the margins of safety and the probability that an initial shock is magnified. Other definitions can be traced to Tsomocos (2003) or Caballero and Krishnamurthy (2009). We contribute to this literature by putting forward a methodology that is able to isolate the contribution of a country to the fragility of an entire system. This isolation process is conducted in an absorption ratio -based approach. The empirical section focuses on a group of Eastern European countries and demonstrates their individual impact on the fragility of the Eastern European capital market. In order to test for robustness we employ the economic SentiMent indicator issued by the European Commission. This is a composite indicator comprising of five indicator specifications for: industrial confidence, construction confidence, services confidence and retail trade confidence. In our analysis, this aggregate is implemented in a panel framework alongside the difference between the Absorption Ratio for the whole Eastern European financial system and the Absorption Ratio of the system less the respective country.

The remainder of this paper is organized in the following way. Section two offers a brief literature review that focuses on the use of the absorption ration as a measure of systemic risk. Section three deals with the data incorporated in the study 
Stock Market Fragility for Macroprudential Policies in Eastern European Countries

and with the methodological specifications. Section four presents the results obtained, while section five concludes.

\section{Review of the scientific literature}

Given the relevance of systemic risk measurement, the specific literature numbers numerous significant contributions that aim at formulating or reviewing computational methods.

Our paper builds on the results of Kritzman, Li, Page, and Rigobon (2011) that offer the first formulation of the absorption ratio (AR) as a measure of systemic imbalances. The authors define the absorption ratio as the fragment of the entire variance of a series of returns that is explained or in this context "absorbed" by a specified number of eigenvectors. Kritzman, Li, Page, and Rigobon (2011) argue that when the markets are powerfully linked, they are more sensible to the propagation of adverse shocks than in a scenario in which market interconnections are lower.

The logic of the AR starts with assuming the existence of a covariance matrix of asset returns specific to a particular time frame. In this setup, the first eigenvector which is defined as a linear combination of asset proportions (weights) will account for the largest segment of the total variance. Besides this, the second eigenvector which is also a linear combination of asset proportions considered orthogonal to the first one will account for the largest segment of the remaining variance after the absorption of the first eigenvector. On the same pattern, the third and following eigenvectors will absorb the greatest proportion of the remaining variance being orthogonal to precursory vectors. (Kritzman, Li, Page, and Rigobon (2011)).

Under these specifications that we will later extend, a high value of the AR indicates a large level of systemic risk as it hints to the idea that the sources of risk are congruent. On the other hand, a low AR value denotes a low level of systemic risk given the fact that in this case the sources of risk are dissimilar.

Given the tractability of the absorption ration formulation, it quickly got implemented in a series of investigations aiming at systemic risk.

Kinlaw, Kritzman and Turkington (2012) use the approach found in Kritzman et al (2011) and compute daily AR values for a 500 day rolling window that incorporates a 250 day half-life exponential decay. Kinlaw et al firstly calculate a measure entitled standardized shift of the AR by computing the average for the most recent 15 days, subtracting the precedent annual average and then dividing the result by the standard deviation of the AR for the same time frame. Mathematically, the approach found in Kinlaw and al can be expressed in the following way:

$$
\Delta A R=\left(A R_{15 \text { days }}-A R_{1 \text { year }}\right) / \sigma
$$


The most significant contribution found in Kinlaw, Kritzman and Turkington (2012) resides in their specification for centrality. The construction of this measure navigates around three main pillars: capturing asset vulnerability, capturing the linkages of one asset with the others in the system and capturing the risk profile of the other assets that are related to the target asset.

The centrality measure has the following formulation:

$$
C S_{i}=\frac{\sum_{j=1}^{n}\left(A R^{j} \frac{\left|E V_{i}^{j}\right|}{\sum_{k=1}^{N}\left|E V_{k}^{j}\right|}\right)}{\sum_{j=1}^{n} A R^{j}}
$$

where

$C S_{i}$ centrality measure;

$A R^{j}$ absorption ration for the $\mathrm{j}$ eigenvector;

$E V_{i}^{j}$ absolute value of the exposure of asset $\mathrm{i}$ in eigenvector $\mathrm{j}$;

$n$ number of eigenvectors;

$N$ number of assets.

Meng et al (2014) study the systemic risk for the US real estate market for the 1975 -2011 interval, incorporating in their approach a specification for the absorption ratio. The authors observe that the absorption ratio begun to swell significantly in 2003 and since them remains at historical high values. This led the authors to argue that systemic risk was at a historical maximum after the climax of the housing bubble.

Reynold, Shnyra and Stein (2015) combine the principal component analysis building block of the classic AR with a structural default model in order to obtain a new systemic risk measure. This innovation is called credit absorption ratio (CAR) and has the following formulation:

$$
C A R_{t}=\frac{\lambda_{1 t}}{\sum_{j=1}^{m} \lambda_{j t}}
$$

where

$\lambda_{j}$ represents the variance of $j^{\text {th }}$ eigenvector.

The authors notice the fact that times of financial uncertainty and difficulty are preceded by increases in CAR. The financial interpretation of the measure resides in the fact that it detects connections between the credit fundamentals for both markets and companies.

Dumitrescu (2015) focuses on the efficiency of the AR as a turbulence indicator for the EU financial markets in the 2000 - 2015 time frame. Dumitrescu (2015) employs an event study methodology and observe that modifications of the AR 
Stock Market Fragility for Macroprudential Policies in Eastern European Countries

with a magnitude greater than one standard deviations forecast episodes of financial contractions.

Giglio, Kelly and Pruitt (2015) survey and test a large battery of systemic risk measures aiming on their capacity to predict macroeconomic distress. The authors include the absorption ratio among other 18 measures and when testing the entire batch for the US and Europe observe that AR, CoVAR, GZ, MES and $\triangle \mathrm{CoVaR}$ tend to comove.

Gordon (2015) aims at determining a stability indicator for the Jamaican banking system. In a PCA setup that considers the absorption ration, the author concludes that AR changes are useful in the monitoring of the financial conditions for the case of Jamaica

\section{Data and methodology}

As input data we are using daily value of total market indices collected from Thompson Reuters Datastream for: Romania, Bulgaria, Poland, Czech Republic and Hungary. The data cover the January 2013 - October 2016 interval. Figure 1 shows the statistical properties of this data series.

Figure 1 - Distribution of log-returns for the Eastern European stock indices

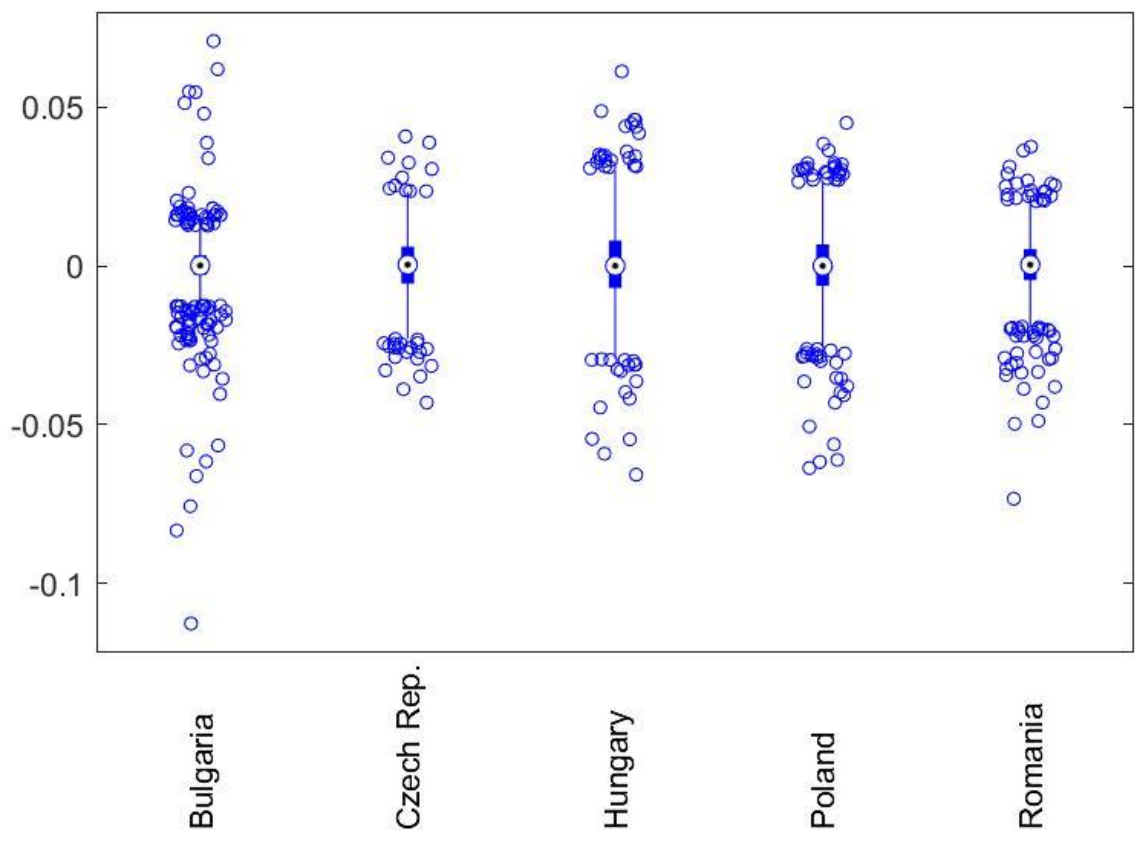

Source: Authors' computation 
In order to test for robustness we employ an European Sentiment indicator. This is a composite indicator comprising of five indicator specifications for: industrial confidence, construction confidence, services confidence and retail trade confidence.

As previously stated, our investigation incorporates the AR measure, introduced by Kritzman, Li, Page, and Rigobon (2011). Its general specification is the following:

$$
A R=\frac{\sum_{i=1}^{N} \sigma_{E_{i}}^{2}}{\sum_{j=1}^{N} \sigma_{A_{j}}^{2}}
$$

where:

$A R$ - absorption ratio;

$\mathrm{N}$ - number of assets;

$\mathrm{n}$ - number of eigenvectors;

$\sigma_{E_{i}}^{2}$ variance of eigenvector I;

$\sigma_{A_{j}}^{2}$ variance of asset $\mathrm{j}$.

Our approach assumes two types of investigations. Firstly, we compute the absorption ratio for the return series of the above mentioned financial assets and comment on the results. In addition to this, our second analysis focuses on computing the AR on the standard deviations that derive from a simple GARCH $(1,1)$ model. The GARCH model derives from the research conducted by Bollerslev (1986) and consists in a generalization of the ARCH process introduced by Engle (1982). The general form of the model is given by the following equation:

$$
\sigma_{t}^{2}=\alpha_{0}+\sum_{i=1}^{m} \alpha_{i} a_{t-i}^{2}+\sum_{j=1}^{s} \beta_{j} \sigma_{t-j}^{2}
$$

where

$$
\alpha_{0}>0, \alpha_{i} \geq 0, \beta_{j} \geq 0
$$

and

$$
\sum_{i=1}^{\max (m, s)}\left(\alpha_{i}+\beta_{i}\right)<1
$$


Stock Market Fragility for Macroprudential Policies in Eastern European Countries

\section{Results and discussion}

The dynamics for the volatilities are presented in Figure no 2. As mentioned in the methodology section, we employed the simple $\operatorname{GARCH}(1,1)$ to estimate the values of the variances. The figure exhibits the values of the annual volatilities.

Figure 2 - Annual volatilities for each country in our sample
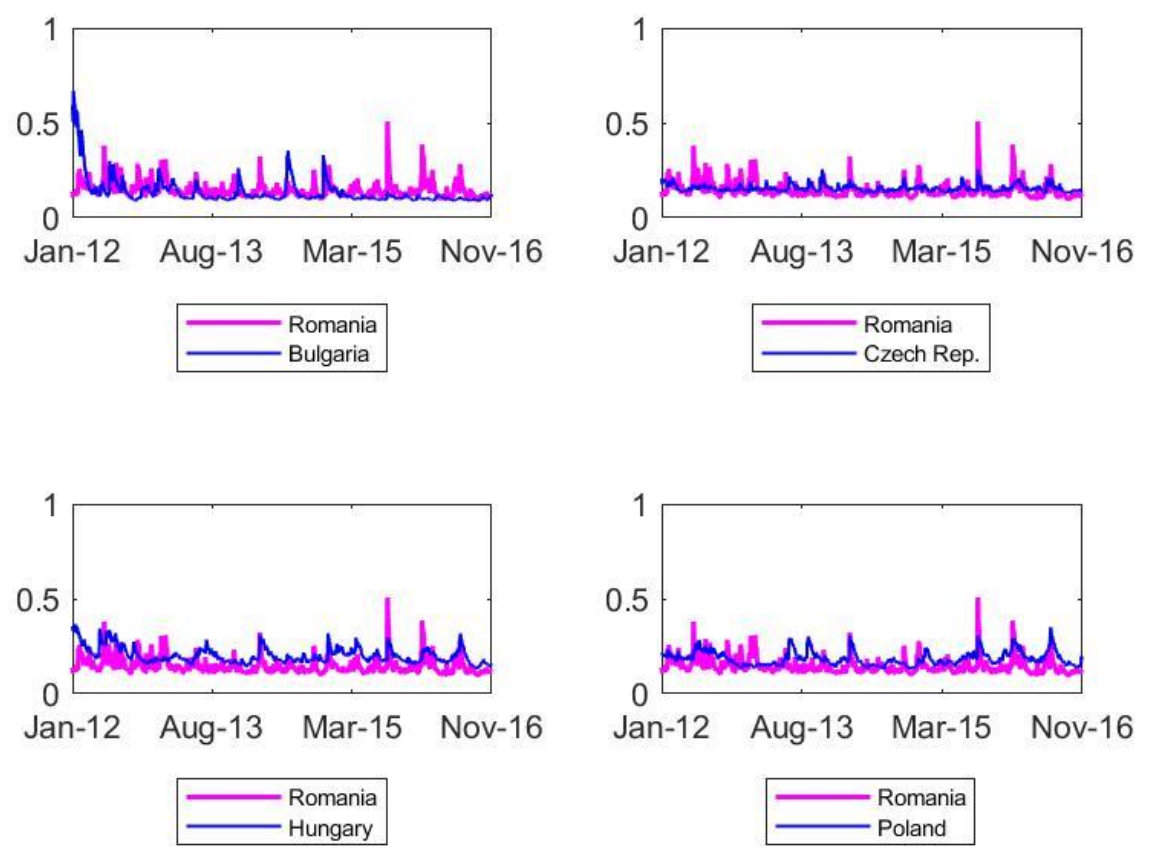

Source: Authors' computation Further, our analysis provides a measure of the level of diversification benefit that each of the indices in our analysis could provide to the whole system of variation. According to Kritzman, Li, Page, and Rigobon (2011), we develop measures of systemic risk for all the national stock markets in our sample and monitor their evolution. Figure no. 1 shows that these measures are rather stable, with a smooth positive trend that could coincide with the volatility specific to the period post Brexit vote. 


\section{Figure 3 - The AR for the group as opposed to AR for the group less each country - $\log$ returns}
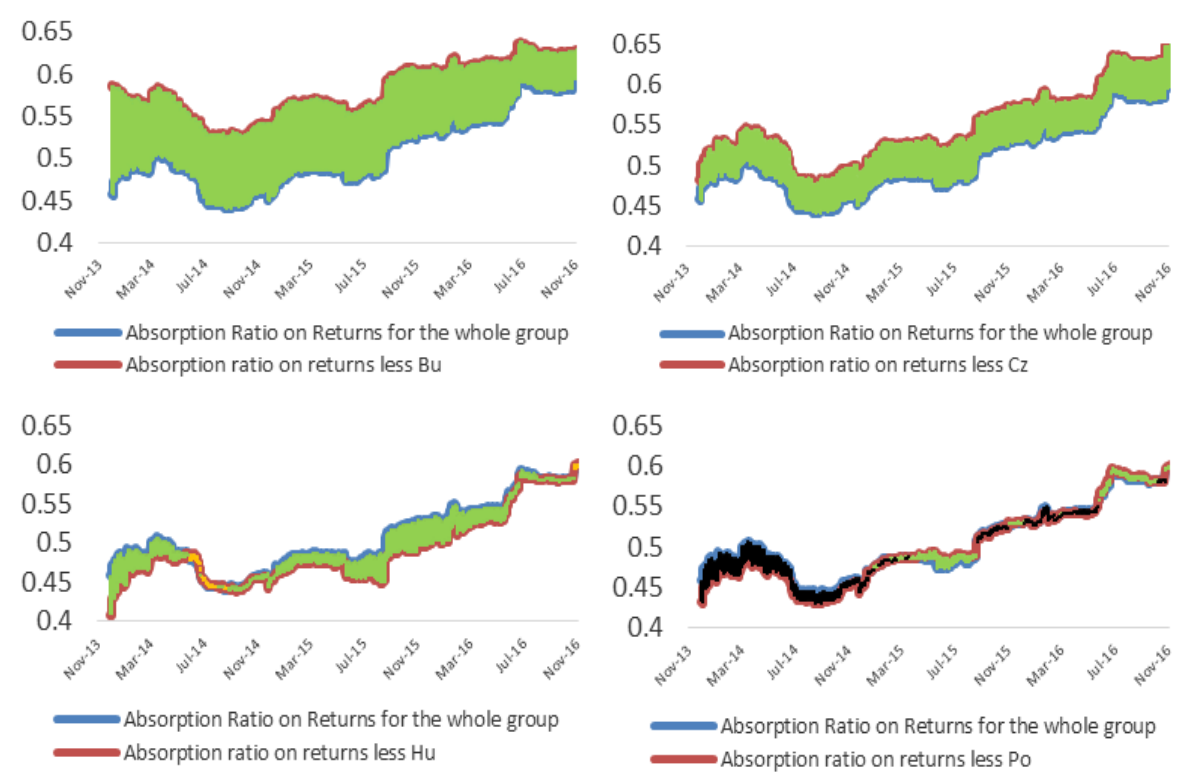

Source: Authors' computation

Developed as the principal component of the log-returns of the indices, the Absorption Ratio (AR) captures the measure of the commonality of factors existent in the dynamics of national stock market indices, without any information of the contribution of each of these indices to the level of systemic risk. We therefore decided to use the measure of the AR for the whole group, from which we subtracted each stock index. In this way, we can analyze the contribution of each national index to the systemic risk of the group by means of comparison between the Absorption ratios of the two groups (one that consists in all countries and a second one without a certain country).

Under this approach, we can conjecture that the difference between the first component of the PCA for the whole group and the first component of the PCA for the group without a certain index corresponds to the contribution of that index to the common variation of the whole group. If the returns generated by the first component for all the countries in the group represent the systemic performance, i.e. the performance of a diversified portfolio, then the difference is the lack in performance generated by the absence of one of the assets. 
Stock Market Fragility for Macroprudential Policies in Eastern European Countries

According to this assertion, we can consider that when the values of the AR for the whole group are higher than the ones for the group without one country, then the inclusion of the country in the portfolio will increase the fragility of the system. An inverse situation will correspond to a decrease of the fragility of the system, which can be regarded as a measure of diversification benefit.

Figure 3 shows that when added to the portfolio, both Bulgaria and the Czech Republic decrease the systemic risk, while Hungary and Poland tend to magnify the level of fragility, even though this increase seems to be rather reduced.

Figure 4 - Changes in AR and changes in differences in AR - log-returns

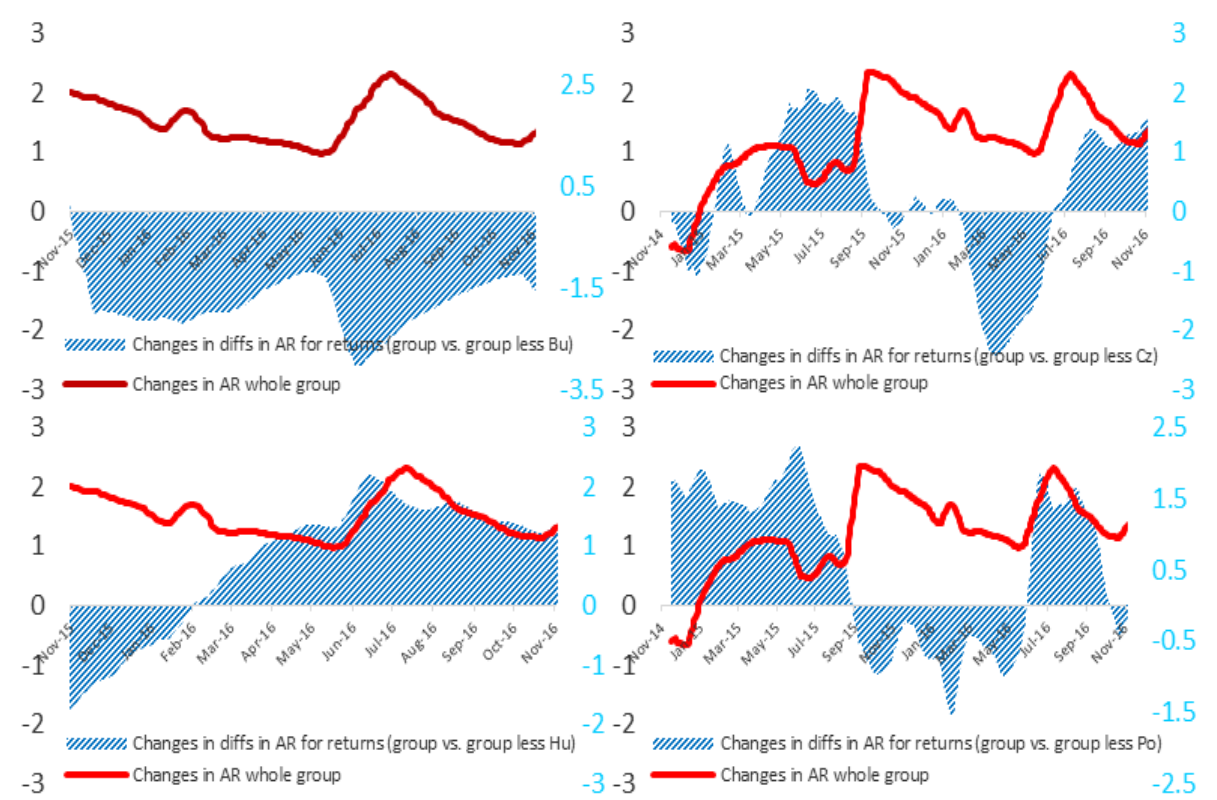

Source: Authors' computation

Furthermore, Figure 4 shows the trend of the impact of each country to the systemic risk of the whole group. We notice that the fragility increased since 2015 but suffered important changes immediately after the Brexit vote. In the last part of 2016 the AR plunged to the levels recorded only in September 2015.

As far as the benefit of diversification is concerned, we notice that the changes in the impact of Bulgaria's inclusion in the portfolio are negative, which means that, even though the inclusion of Bulgaria in the portfolio reduces the level of fragility, to extreme shocks, this benefit is reducing as time passes. We can conjecture that, according to the same reasoning, the Czech Republic, Hungary and Poland tend to improve the fragility of the system in the last part of our sample. 
Figure 5 - The AR for the group as opposed to AR for the group less each country - volatilities
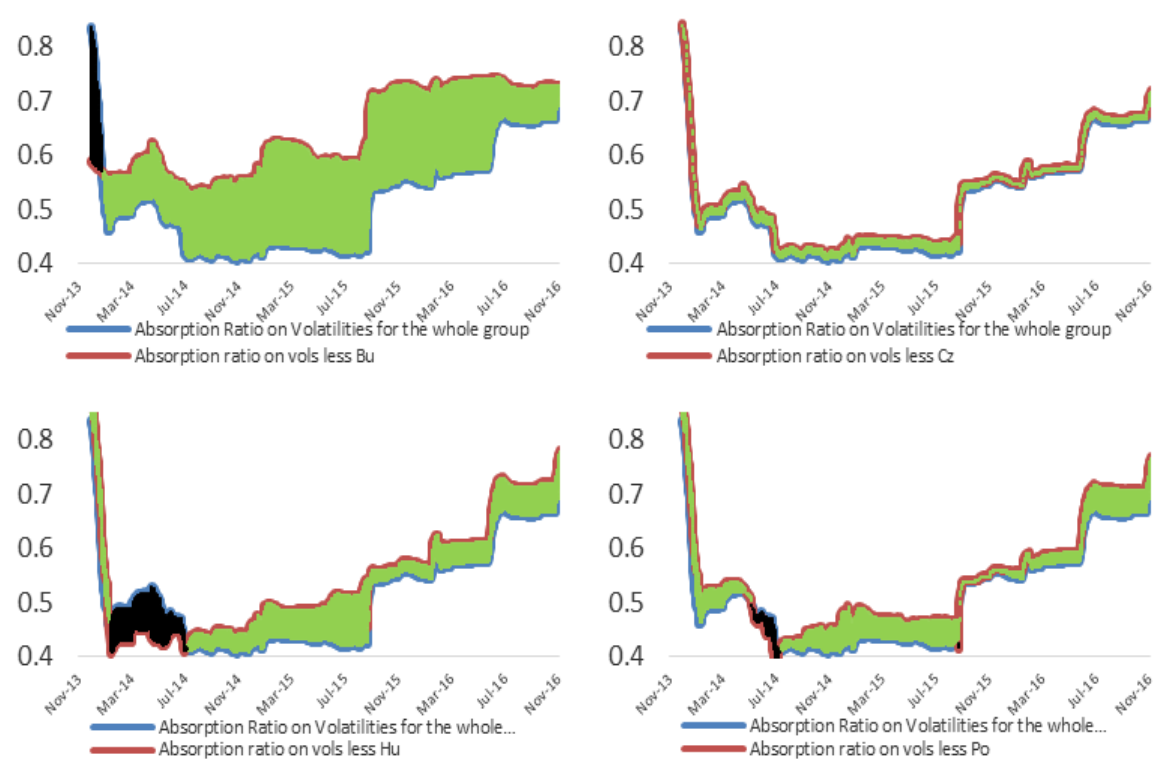

Source: Authors' computation

To develop our analysis even further, as mentioned in the methodology section, we extended the AR tool to the set of conditional variances. Figure 5 shows the evolution of the same ratios for the case of conditional volatilities, estimated with the abovementioned GARCH model. We notice a similar situation for the volatilities as in the case of the log-returns, i.e. Bulgaria contributes to the level of fragility of the systemic risk as depicted by the changes in volatilities. Furthermore, the common factors determining the sources of risk are increasing as time passes.

The AR for the volatilities could be interpreted as the fragility of the investors' beliefs, since the methodology relates to the dynamics of variances for the volatilities, i.e. the kurtosis of the series of stock returns. We can therefore consider that these values represent a gauge for the level of co-kurtosis, existent in the whole portfolio, i.e. the quantification of fat-tail expectation, which is a measurement of fear. 
Stock Market Fragility for Macroprudential Policies in Eastern European Countries

\section{Figure 6 - Changes in AR and changes in differences in AR - volatilities}

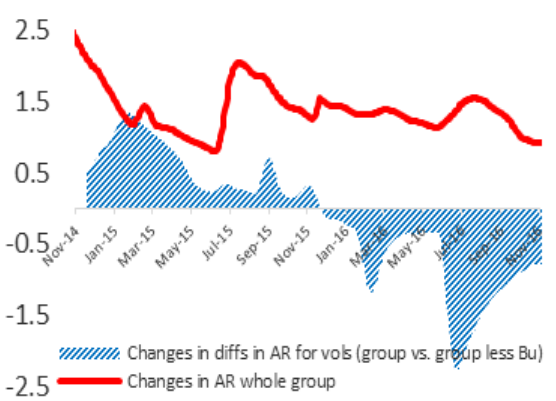

$4 \quad 4$

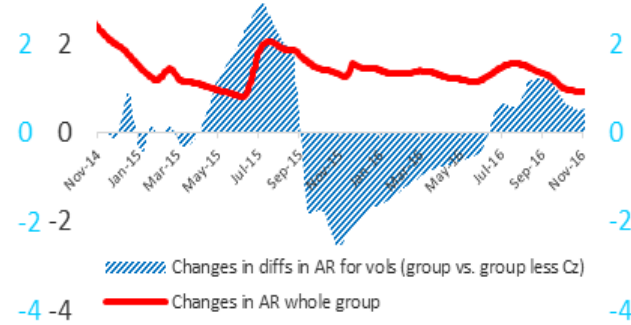

4

34

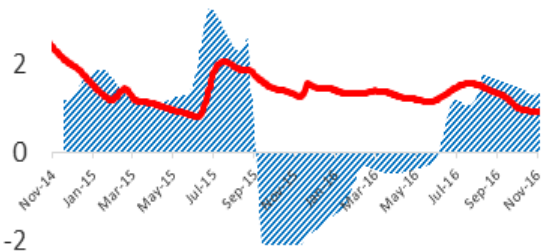

IIIIIIII, Changes in diffs in AR for vols (group vs. group less Hu)

$-4 \longrightarrow$ Changes in AR whole group

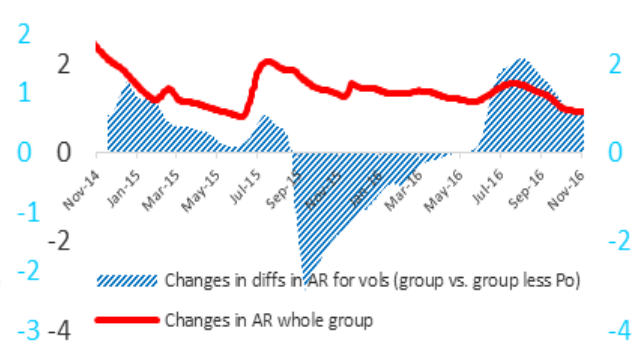

Source: Authors' computation

Figure 6 shows that under the reduction in the level of common sources of systemic kurtosis, all the countries in the charts succeed to reduce the systemic level of fat-tailness. This means that the portfolio comprising all the assets performs better in terms of systemic kurtosis, therefore reduces the propensity to have fat tails and reduces the amount of fear in the markets.

Figure 7 - Dynamics of AR for log-returns and volatilities for Romania

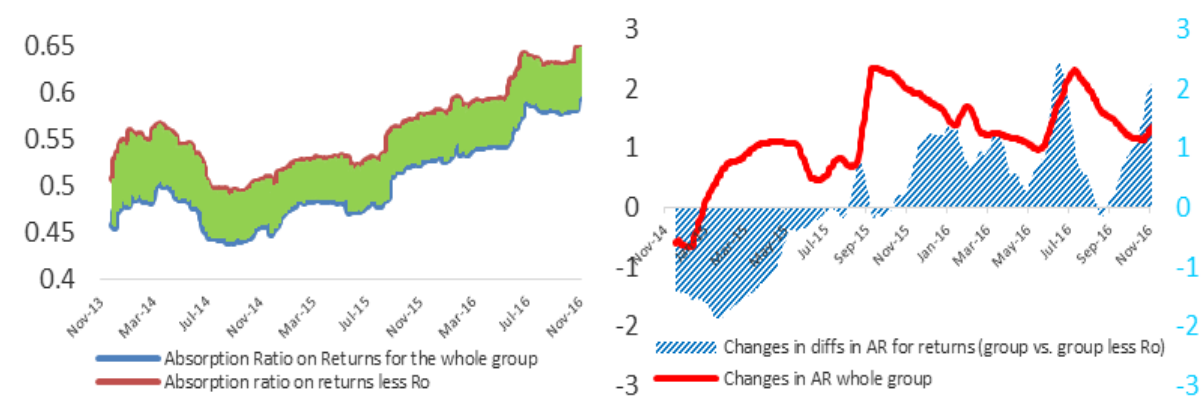




\section{Radu Lupu, Adrian Cantemir Calin, Ana Barbara Bobirca, Paul Gabriel Miclaus}
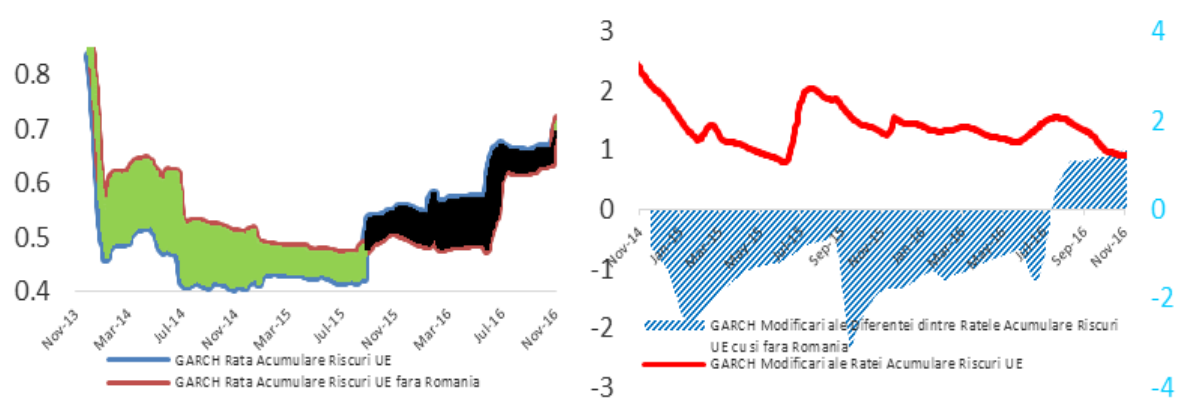

Source: Authors' computation

In the case of Romania, we notice that the contribution to the systemic risk is positive, which means that, when Romania is included in the portfolio, the fragility is lower on average. An increase of this effect takes place especially at the end of the sample we analyzed. As far as the set of variances is concerned, we notice that we are dealing with two periods: one that spans the November 2013 - November 2015 time interval and depicts a situation in which Romania reduces the level of systemic kurtosis; a second one that covers the period from November 2015 to November 2016 and reflects a period in which Romania increases the systemic kurtosis of the group. We can notice also that this phenomenon tends to decrease by the end of the sample.

In order to understand the importance of these indicators for political decision-making, our analysis focused on the connections that they have with perceptions of economic policies. We therefore used the set of economic policy SentiMent indicators issued by the European Commission for the countries included in our sample.

We built a panel for the five Eastern European member states in which we used the difference between the Absorption Ratio for the whole Eastern European financial system minus the Absorption Ratio of the system less the respective country as dependent variable. The SentiMent indicator corresponding to this country was the explanatory variable.

Table 1: Results of Hausman test on the panel regression

\begin{tabular}{lllll}
\hline Variable name & $\begin{array}{l}\text { Fixed } \\
\text { Effects }\end{array}$ & $\begin{array}{l}\text { Random } \\
\text { Eeffects }\end{array}$ & $\begin{array}{l}\text { Coef. } \\
\text { Diff }\end{array}$ & $\begin{array}{l}\text { S.E. } \\
\text { Diff }\end{array}$ \\
\hline $\begin{array}{l}\text { SentiMent } \\
\text { Indicator }\end{array}$ & 0.002112 & 0.001972 & 0.00014 & 0 \\
$\begin{array}{l}\text { SentiMent } \\
\text { Indicator (lag 1) }\end{array}$ & 0.004202 & 0.004098 & 0.000105 & 0 \\
\hline
\end{tabular}

Source: Authors' computation

The results for Hausman test are presented in Table 1. The test compares the coefficients of the Fixed Effects specification against the Random Effects one and 
Stock Market Fragility for Macroprudential Policies in Eastern European Countries

provided a value of 65.63491 , which corresponds to a p-value that is virtually 0 , which means that the fixed effects specification is suggested for our analysis.

Table 2: Fixed effects estimation

\begin{tabular}{lllll}
\hline & Coefficient & Std.Err & t-stat & p-value \\
\hline SentiMent & 0.001332 & 0.000495 & 2.6923 & $0.007 * * *$ \\
SentiMent (lag 1) & -0.00043 & 0.000494 & -0.8651 & 0.387 \\
\hline & & \multicolumn{3}{c}{ Source: Authors' computation }
\end{tabular}

Table 2 presents the results of the fixed effects estimation. We notice that our value for the Absorption Ratio for returns is dependent on the contemporaneous dynamics of the SentiMent indicator, which means that the evolution of perceptions with respect to economic policies in a certain country tend to influence the evolution of the contribution of each country to the fragility of the Eastern European capital market system.

\section{Conclusions:}

Using a sample of Eastern European stock market indices, we used a methodology that employs the Principal Component Analysis to develop measures of the contribution of each country to the systemic risk of the whole group and investigated these effects on a four-year interval, covering 2013 to 2016. We analyzed the effect of each country and noticed their contribution to the reduction or increase of the fragility. We further used the same methodology for the set of variances computed with a simple GARCH $(1,1)$ model for the same sample.

This investigation set the ground for the development of a new indicator of systemic kurtosis, which could be seen as the measurement of fear existing in these markets, as it shows the variation of risk and the propensity of the system to generate fat tails. We showed that the inclusion of more indices in a portfolio determines the reduction of systemic fat-tail-ness, which is a representation of co-kurtosis.

A check for the significance of our analysis consisted in the analysis of the connection of the differences between the Absorption Ratio for the whole European financial system and the Absorption Ratio for the same system less each of the countries in our sample. This variable shows the contribution of each country to the financial fragility of the whole system. We investigated the economic significance of this variable by running a panel regression in which we used the Economic SentiMent indicator, issued by the European Commission, as explanatory variables for each country. The results show that there is a strong connection between this indicator and the values of our measures of contribution to fragility. 
Radu Lupu, Adrian Cantemir Calin, Ana Barbara Bobirca, Paul Gabriel Miclaus

\section{REFERENCES}

[1] Bollerslev, T. (1986), Generalized Autoregressive Conditional heteroskedasticity. Journal of Econometrics, 31 pp. 307-327;

[2] Borio, C. (2003), Towards a Macroprudential Framework for Financial Supervision and Regulation?; CESifo Economic Studies, 49, pp. 181-216;

[3] Borio, C. (2013), The Financial Cycle and Macroeconomics: What Have we Learnt?; Journal of Banking \& Finance, 45, pp. 189-198;

[4]Caballero, R., Krishnamurthy, A. (2009), Global Imbalances and Financial Fragility; American Economic Review, 99(2), pp. 584-88;

[5]Crockett, A. (2000), Marrying the Micro- and Macro-Prudential Dimensions of Financial Stability. Speech at the Eleventh International Conference of Banking Supervisors, Basel;

[6]Dumitrescu S. (2015), Turbulence and Systemic Risk in the European Union Financial System; Financial Studies, Nr. Special ASF;

[7]Engle, R. F. (1982), Autoregressive Conditional Heteroscedasticity with Estimates of the Variance of United Kingdom Inflation; Econometrica, 50, pp. 987-1007; [8]Galati, G., Moessner, R. (2013), Macroprudential Policy: A Literature Review; Journal of Economic Surveys, 27, 846878;

[9]Giglio, S., Bryan T. Kelly Seth, Pruitt (2015), Systemic Risk and the Macroeconomy: An Empirical Evaluation; National Bureau of Economic Research, Working Paper 20963;

[10]Gordon, L.R. (2015), The Absorption Ratio as an Indicator for Macroprudential Monitoring in Jamaica; Bank of Jamaica; [11]International Monetary Fund, (2011), Macroprudential Policy: An Organizing Framework, prepared by the Monetary and Capital Markets Department in consultation with Research and other departments; [12]Kinlaw, W., Kritzman, M. and Turkington, D. (2012), Toward Determining Systemic Importance; The Journal of Portfolio Management, 38(4), pp. 100-111; [13]Knight, M.D. (2006), Marrying the Micro- and macroprudential Dimensions of Financial Stability: Six Years on. Speech delivered at the 14th International Conference of Banking Supervisors, Mrida; [14]Kritzman, M., Li, Y., Page, S., and Rigobon, R. (2011), Principal Components as a Measure of Systemic Risk; The Journal of Portfolio Management, 37(4); 
Stock Market Fragility for Macroprudential Policies in Eastern European Countries

[15]Meng, H., Xie, W.-J., Jiang, Z.-Q., Podobnik, B., Zhou, W.-X., Stanley, H. E. (2014), Systemic Risk and Spatiotemporal Dynamics of the US Housing Market. Sci. Rep. 4, 3566;

[16]Reyngold, A., Shnyra, K. and Stein, R. (2015), Aggregate and Firm-level Measures of Systemic Risk from a Structural Model of Default; The Journal of Alternative Investments, 17( 4 ), pp. 58-78;

[17]Tsomocos, D.P. (2003), Equilibrium Analysis, Banking, Contagion and Financial Fragility; Bank of England Working Paper No. 175;

[18]Tymoigne, E. (2014), Measuring Macroprudential Risk through Financial Fragility: A Minskian Approach; Journal of Post Keynesian Economics, 36(4); [19]White, W. (2006), Procyclicality in the Financial System: Do we Need a New Macrofinancial Stabilisation Framework?, BIS Working Papers, no. 193. 